\title{
Regulation of Gene Expression by Chronic Morphine and Morphine Withdrawal in the Locus Ceruleus and Ventral Tegmental Area
}

\author{
Colleen A. McClung, ${ }^{1}$ Eric J. Nestler, ${ }^{1}$ and Venetia Zachariou ${ }^{1,2}$ \\ ${ }^{1}$ Department of Psychiatry and Center for Basic Neuroscience, The University of Texas Southwestern Medical Center, Dallas, Texas 75390-9070, and \\ ${ }^{2}$ Faculty of Medicine, Department of Basic Sciences, University of Crete, Heraklion, Crete 71003
}

\begin{abstract}
Morphine dependence is associated with long-term adaptive changes in the brain that involve gene expression. Different behavioral effects of morphine are mediated by different brain regions, for example, the locus ceruleus (LC), a noradrenergic nucleus, is implicated in physical dependence and withdrawal, whereas the ventral tegmental area (VTA), a dopaminergic nucleus, contributes to rewarding and locomotor responses to the drug. However, the global changes in gene expression that occur in these brain regions after morphine exposure and during withdrawal remain unknown. Using DNA microarray analysis in both mice and rats, we now characterize gene expression changes that occur in these brain regions with chronic morphine and antagonist-precipitated withdrawal. In the LC, numerous genes display common regulation between mouse and rat, including tyrosine hydroxylase, prodynorphin, and galanin. Furthermore, we identify clusters of genes that are regulated similarly by chronic morphine and by withdrawal, as well as clusters that show opposite regulation under these two conditions. Interestingly, most gene expression changes that occur in the VTA in response to chronic morphine are different from those seen in the LC, but the gene expression patterns in the two brain regions are very similar after withdrawal. In addition, we examined two genes (prodynorphin and FK506 binding protein 5) that are strongly regulated by chronic morphine or morphine withdrawal in the LC for their role in regulating withdrawal-associated behaviors. Inhibition of either protein profoundly affects withdrawal responses, demonstrating that the genes identified in this study have important functional roles in mediating opiate-induced behaviors.
\end{abstract}

Key words: drug abuse; DNA microarray; opiate addiction and withdrawal; noradrenergic; dopaminergic; dynorphin; FKBP5

\section{Introduction}

Morphine and other opiates are highly abused substances that exert their effects via G-protein-coupled $\mu$-opioid receptors ( $\mathrm{Na}$ rita et al., 2001; Kieffer and Gaveriaux-Ruff, 2002). The consequences of repeated opiate use include increased drug craving, tolerance to opiate analgesia, and expression of a withdrawal syndrome when the drug is discontinued (Kreek, 2001; Inturrisi, 2002). Each of these features is a result of adaptive changes in several neuronal networks. One of the best-characterized brain regions for the cellular adaptations that occur during prolonged activation of $\mu$-opioid receptors is the locus ceruleus (LC), a major noradrenergic nucleus in the anterior pons (Aghajanian and Wang, 1986; Harris and Williams, 1991; Nestler and Aghajanian, 1997; Ivanov and Aston-Jones, 2001; Alvarez et al., 2002; Nakai et al., 2002). Increased activity of LC neurons is responsible

Received March 25, 2004; revised May 9, 2005; accepted May 14, 2005.

This work was funded by grants from the National Institute on Drug Abuse. We thank the microarray core facility at University of Texas Southwestern for technical support, especially Minning Wu and Anwu Zhou. We also thank Bryan Potts and Steve Gold for technical assistance.

Correspondence should be addressed to Colleen A. McClung, Department of Psychiatry and Center for Basic Neuroscience, The University of Texas Southwestern Medical Center, 5323 Harry Hines Boulevard, Dallas, TX 753909070. E-mail: colleen.mclung@utsouthwestern.edu.

DOI:10.1523/JNEUROSCI.0062-05.2005

Copyright $\odot 2005$ Society for Neuroscience $\quad$ 0270-6474/05/256005-11\$15.00/0 for many of the symptoms observed after withdrawal from the drug. Part of this increased activity is thought to be attributable to changes intrinsic to these neurons, in particular, upregulation of the cAMP signaling pathway and subsequent changes in protein phosphorylation and gene expression (Rasmussen et al., 1990; Guitart et al., 1992; Widnell et al., 1994; Punch et al., 1997; ShawLutchman et al., 2002). Similar adaptive changes after repeated opiate use have been observed in other brain regions, such as the ventral tegmental area (VTA), part of the mesolimbic dopaminergic system, a neuronal network critical for drug reward (Self et al., 1995; Bonci and Williams, 1996, 1997).

Several studies have identified and characterized proteins regulated by opiates in these and other brain regions (Nestler and Aghajanian, 1997). Some of these proteins, such as the transcription factor CREB (cAMP response element-binding protein) and tyrosine hydroxylase (the rate-limiting enzyme in norepinephrine and dopamine biosynthesis), appear to play key roles in the molecular adaptations to chronic opiate exposure in the LC, VTA, and other brain regions (Lane-Ladd et al., 1997; Walters et al., 2003), whereas other proteins appear to be regulated only in specific regions (Nye and Nestler, 1996). Many of these changes in protein levels are thought to be mediated at the level of gene expression, but there has not yet been a large-scale analysis of drug-induced changes in gene expression in the LC or VTA. Bet- 
ter understanding such molecular changes in these neurons could provide new targets for the treatment and prevention of opiate addiction.

Here, we use Affymetrix microarrays to obtain a global profile of genes regulated by chronic morphine and by antagonist precipitated withdrawal in the LC of mice and rats and identify clusters of genes that show similar regulation after chronic morphine versus withdrawal, and others in which the regulation is opposite. In addition, we find that gene expression changes in the LC and VTA are very different in response to chronic morphine, whereas morphine withdrawal produces very similar patterns of gene expression. Furthermore, when two of the genes that we identified in this study, prodynorphin and FK506 binding protein 5 (FKBP5) are inhibited, we find that this dramatically alters withdrawal-associated behavioral responses.

\section{Materials and Methods}

Mice and rats. For all sets of experiments, we used 8- to 12-week-old male C57BL/6 mice (The Jackson Laboratory, Bar Harbor, ME) or male Sprague Dawley rats (Charles River Laboratories, Wilmington, MA) initially weighing $250-275 \mathrm{~g}$. Mice were housed in groups of five and rats in groups of two, in a $12 \mathrm{~h}$ dark/light cycle with food and water available ad libitum. All animal protocols were in accordance with the National Institutes of Health Guide for the Care and Use of Laboratory Animals and were approved by our institutional Animal Care and Use Committee.

Drug treatments. Mice were implanted subcutaneously with $25 \mathrm{mg}$ morphine pellets, with one pellet given on day 1 and a second pellet given on day 3 , and were used on day $6,4 \mathrm{~h}$ after a single saline or naltrexone (50 $\mathrm{mg} / \mathrm{kg}$, s.c.) injection. Rats were implanted with $75 \mathrm{mg}$ morphine pellets daily for $5 \mathrm{~d}$, and animals were used on day $6,4 \mathrm{~h}$ after a single saline or naltrexone $(50 \mathrm{mg} / \mathrm{kg}$, s.c.) injection. Control animals received sham surgery followed by saline or naltrexone injections. For all studies, four groups of animals were used: (1) sham-saline (control), (2) morphinesaline (chronic morphine), (3) sham-naltrexone (naltrexone), and (4) morphine-naltrexone (withdrawal). These treatment conditions were based on substantial evidence for their ability to induce high levels of morphine dependence in the chronic morphine condition and high levels of opiate withdrawal in the withdrawal condition (Shaw-Lutchman et al., 2002; Gold et al., 2003).

Tissue preparation and RNA extraction. Brains were removed and punches were taken from the LC or VTA as described previously (Fitzgerald et al., 1996; Gold et al., 2003). The tissue was then immediately frozen. RNA was isolated from pooled tissue samples from three to five mice or rats using Trizol reagent (Invitrogen, San Diego, CA) according to the instructions of the manufacturer. RNA was subjected to DNAase treatment for 30 min using the DNA free system according to instructions of the manufacturer (Ambion, Austin, TX).

Microarray analysis. Microarray analysis was performed as described previously (McClung and Nestler, 2003) with few modifications. Briefly, total RNA ( $5 \mu \mathrm{g}$ per array isolated from pools of tissue from three to five mice or rats) was converted to cDNA, amplified, and labeled according to the Affymetrix (Santa Clara, CA) protocols [reagents for the single- and double-strand cDNA synthesis were from Invitrogen, and the in vitro transcription and biotin labeling were performed using the ENZO IVT kit from Affymetrix. cRNA was not used if the total RNA recovered after amplification was $<30 \mu$ g or if the $260 / 280$ ratio was less then 1.9 . For the mouse, we used the murine genome U74AV2 array $(\sim 12,500$ transcripts). For the rat, we used the rat genome U34A array ( $\sim 8000$ transcripts). Both arrays were from Affymetrix. RNA fragmentation, hybridization, washing, and scanning were also performed according to the instructions of the manufacturer (Affymetrix). The raw data were initially analyzed using Microarray suite version 5.0 (Affymetrix). All values were scaled to a target value (250) to normalize the expression and allow us to compare arrays. Arrays were judged as acceptable for additional analysis if the $3^{\prime} / 5^{\prime}$ ratios of glyceraldehyde-3-phosphate dehydrogenase (GAPDH) and $\beta$-actin were less then 3 , the percentage of genes on the array considered to be present was $>40 \%$, and if the scaling factors were comparable from array to array. Chronic morphine and withdrawal animals were directly compared with control and naltrexone animals that were treated and dissected at the same time. This was performed two or three times, producing duplicate or triplicate arrays from completely separate groups of animals. Arrays were directly compared using Microarray suite version 5.0. The values taken from comparison files were imported into Genespring (Silicon Genetics, Redwood City, CA) for additional analysis and data visualization. In each replicate, genes were considered to be regulated if the signal was $>40$ and considered "present" by Microarray suite version 5 in the experimental group (or control group in the case of downregulated genes), the $\log _{2}$ ratio of experimental/control was more than 0.3 or less than -0.3 , and the comparison $p$ value (using the nonparametric Wilcoxon's signed-rank test) was $<0.01$. The Benjamini Hochberg method for false discovery rates was used comparing the computed $p$ values with the adjusted $p$ values (Benjamini and Hochberg, 1995), and the false discovery rate was calculated to be $\sim 0.1 \mathrm{in}$ all arrays. Only genes that met these criteria in all sets of arrays were considered significantly regulated.

In addition, we performed a control study to determine the amount of biological, environmental, and technical variability in our system using wild-type, untreated C57BL/6 mice. Samples from these mice were run on four arrays and analyzed using the statistical methods outlined above. We found that only 16 of 45,038 transcripts were significantly different among these control replications. These findings indicate that very few $(\sim 0.035 \%)$ of the regulated transcripts identified in this study might show regulation attributable to external variables.

Real-time PCR. We confirmed gene expression changes by real-time PCR for 26 genes that were regulated on our arrays (supplemental Tables S7, S9, available at www.jneurosci.org as supplemental material). RNA was extracted from pooled tissue punches from two groups of three to five animals. These groups were separate from those used in the array study. The RNA was converted to cDNA using Superscript II reverse transcriptase according to the instructions of the manufacturer (Invitrogen). Twenty-five microliter PCR reaction mixtures contained cDNA, Fast start LC SYBR green master mix (Roche Products, Welwyn Garden City, UK), $\mathrm{MgCl}_{2}, \mathrm{H}_{2} \mathrm{O}$, and custom primers designed for each gene of interest. The PCR reactions were performed in the Light Cycler (Cepheid, Sunnyvale, CA). Each reaction was performed in duplicate, and threshold cycles $\left(\mathrm{C}_{\mathrm{T}}\right)$ were calculated using the second derivative of the reaction. The $\mathrm{C}_{\mathrm{T}}$ of each gene was normalized against that of GAPDH, which shows no regulation by morphine under any condition on our microarrays. Fold changes were determined using the $-\Delta \Delta \mathrm{C}_{\mathrm{T}}$. RNA controls were performed to ensure that amplification of products did not come from genomic DNA contamination. Statistical significance was determined by $t$ tests.

In situ hybridization. Mice were treated chronically with morphine pellets or sham surgery as described above, followed by an injection of naltrexone (for the withdrawal group). Four hours later, brains were removed and frozen. Tissue was sectioned in a cryostat at $12 \mu \mathrm{m}$. RNA probes for prodynorphin and FKBP5 were prepared and labeled with ${ }^{35} \mathrm{~S}$ by incorporation during in vitro transcription using T7 RNA polymerase as described previously (Gold et al., 2003). Tissue sections were fixed in $4 \%$ paraformaldehyde, washed, acetylated, dehydrated, and incubated with probe $\left(10 \times 10^{6} \mathrm{cpm} / \mathrm{ml}\right)$ in hybridization buffer $(20 \mathrm{~mm}$ Tris- $\mathrm{HCl}$, pH 7.5, 1 mм EDTA, $1 \times$ Denhardt's solution, $335 \mathrm{~mm} \mathrm{NaCl}$, 50\% deionized formamide, $10 \%$ dextran sulfate, $0.3 \mathrm{mg} / \mathrm{ml}$ salmon sperm DNA, $0.15 \mathrm{mg} / \mathrm{ml}$ yeast tRNA, and $80 \mathrm{~mm}$ DTT, in DEPC- $\mathrm{H}_{2} 0$ ) overnight at $60^{\circ} \mathrm{C}$. The following day, sections were washed in progressively less concentrated SSC buffers $(4 \times, 2 \times, 0.5 \times$, and $0.1 \times)$ containing $10 \mathrm{~mm}$ sodium thiosulfate, treated with RNase A, dried, and exposed to film. Levels of RNA were quantified by densitometry using NIH Image as described previously (Gold et al., 2003).

Withdrawal behavior. C57BL/6 mice, 8 weeks old, were implanted subcutaneously with two $25 \mathrm{mg}$ morphine pellets, as described above. Three days after the second pellet implantation, opiate withdrawal was precipitated with $50 \mathrm{mg} / \mathrm{kg}$ subcutaneous naltrexone (Sigma, St. Louis, MO), and withdrawal signs (jumps, wet dog shakes, tremor, ptosis, diarrhea, and weight loss) were monitored for 30 min exactly as described previously (Zachariou et al., 2003b). The role of FKBP5 was assessed by use of 
Table 1. Genes regulated by chronic morphine or morphine withdrawal in the LC of both mice and rats

\begin{tabular}{|c|c|c|c|c|}
\hline Gene & Regulation in mice & Fold change & Regulation in rats & Fold change \\
\hline \multicolumn{5}{|c|}{ Genes showing similar regulation in rats and mice } \\
\hline Tyrosine hydroxylase & $\uparrow \mathrm{CM}, \mathrm{MW}$ & $2.4,2.4$ & $\uparrow \mathrm{CM}, \mathrm{MW}$ & $2.1,1.6$ \\
\hline Galanin & $\uparrow \mathrm{CM}, \mathrm{MW}$ & $2.3,1.7$ & $\uparrow \mathrm{CM}, \mathrm{MW}$ & $2.3,1.5$ \\
\hline Prodynorphin & $\uparrow \mathrm{CM}$ & 2.3 & $\uparrow \mathrm{CM}$ & 1.4 \\
\hline Serum/glucocorticoid regulated kinase & $\uparrow \mathrm{CM}$ & 1.9 & $\uparrow \mathrm{MW}$ & 2.0 \\
\hline CD24A antigen & $\uparrow C M$ & 1.5 & $\uparrow \mathrm{MW}$ & 1.5 \\
\hline ATPase, $\mathrm{Na}^{+} / \mathrm{K}^{+} \alpha 1$ & $\uparrow \mathrm{CM}$ & 1.4 & $\uparrow \mathrm{CM}$ & 2.1 \\
\hline Metallothionein 1 & $\uparrow C M$ & 1.3 & $\uparrow M W$ & 2.1 \\
\hline Glutathione S-transferase & $\uparrow \mathrm{CM}$ & 1.3 & $\uparrow \mathrm{MW}$ & 1.3 \\
\hline Glutamate decarboxylase & $\downarrow C M$ & 1.4 & $\downarrow C M$ & 1.4 \\
\hline Farnesyl disphosphate synthetase & $\downarrow \mathrm{CM}, \mathrm{MW}$ & $1.3,1.3$ & $\downarrow \mathrm{MW}$ & 1.4 \\
\hline Glial fibrillary acidic protein $\alpha$ & $\uparrow \mathrm{MW}$ & 2.0 & $\uparrow \mathrm{CM}, \mathrm{MW}$ & $2.0,1.6$ \\
\hline Heat shock protein 70 & $\uparrow \mathrm{MW}$ & 1.6 & $\uparrow \mathrm{CM}, \mathrm{MW}$ & $3.7,3.1$ \\
\hline Metallothionein 2 & $\uparrow M W$ & 1.3 & $\uparrow \mathrm{MW}$ & 3.4 \\
\hline Amyloid $\beta$ (A4) binding protein B & $\uparrow \mathrm{MW}$ & 1.5 & $\uparrow C M$ & 1.4 \\
\hline Brain fatty acid-binding protein & $\downarrow M W$ & 2.0 & $\downarrow M W$ & 1.3 \\
\hline Sterol-C5 desaturase & $\downarrow M W$ & 1.4 & $\downarrow M W$ & 1.5 \\
\hline Guanine nucleotide binding protein $\beta 1$ & $\downarrow M W$ & 1.4 & $\downarrow C M$ & 1.6 \\
\hline \multicolumn{5}{|c|}{ Genes showing opposite regulation in rats and mice } \\
\hline Aquaporin 4 & $\downarrow \mathrm{CM}, \mathrm{MW}$ & $1.3,1.5$ & $\uparrow C M$ & 1.5 \\
\hline Endothelin receptor B & $\downarrow M W$ & 1.4 & $\uparrow \mathrm{CM}$ & 2.0 \\
\hline Prosaposin & $\downarrow M W$ & 1.5 & $\uparrow C M$ & 2.0 \\
\hline
\end{tabular}

The table lists those genes that were significantly regulated $(p<0.01)$ in duplicate arrays in the LC of both mice and rats by chronic morphine versus sham or precipitated withdrawal versus naltrexone treatment alone. $C M$, Chronic morphine; MW, morphine withdrawal.

tacrolimus (Alexis Biochemicals, San Diego, CA), which blocks the actions of this and related proteins (Kaminska et al., 2004). The role of prodynorphin was assessed by use of Nor-binaltorphimine (Nor-BNI), a $\kappa$-opioid receptor antagonist, which blocks the actions of dynorphin (Shippenberg and Rea, 1997). The drugs were used in two ways in separate groups of animals: they were given intraperitoneal injections every morning during the days of chronic morphine treatment or $2 \mathrm{~h}$ before precipitation of opiate withdrawal in morphine-dependent animals. Preliminary studies were conducted to determine the optimal dose and number of administrations necessary for each drug to induce an effect on withdrawal behavior with minimal confounding effects. A dose of 5 $\mathrm{mg} / \mathrm{kg}$ of each compound was found to be optimal.

\section{Results}

\section{Regulation of gene expression in the LC}

The first step in this study was to identify and characterize genes that are regulated by chronic morphine and by antagonistprecipitated morphine withdrawal in the mouse LC. Mice were implanted with two morphine pellets over $6 \mathrm{~d}$, conditions known to cause a high level of morphine dependence and characteristic biochemical changes in this brain region (Shaw-Lutchman et al., 2002). Comparison of chronic morphine with control (sham) conditions revealed significant upregulation of 13 transcripts and downregulation of 13 transcripts by chronic morphine administration (supplemental Table S1, available at www.jneurosci.org as supplemental material). To induce withdrawal, animals were treated as described above and, on day 6, injected with naltrexone, an opioid receptor antagonist, and the animals were used $4 \mathrm{~h}$ later. Arrays from withdrawal animals were compared with those that received naltrexone alone to control for gene expression changes that may be attributable solely to naltrexone treatment. We found an upregulation in 53 transcripts and downregulation in 25 transcripts by morphine withdrawal (supplemental Table S2, available at www.jneurosci.org as supplemental material). Direct comparison of naltrexone animals to control animals revealed a much smaller number of genes that were regulated by naltrexone treatment alone in this brain region (data not shown). We used real-time PCR to verify morphine or withdrawal regu- lation of a subset of genes altered in the LC (supplemental Table S7, available at www.jneurosci.org as supplemental material) and found a false-positive rate of $<10 \%$ (see Discussion).

To determine whether these changes in gene expression observed in the mouse LC are shared across species, we also examined gene expression changes in the LC of rats under similar treatment conditions (see Materials and Methods). In general, a larger number of genes were regulated in the rat versus the mouse (supplemental Tables S1-S5, available at www.jneurosci.org as supplemental material). Fifty-four transcripts were upregulated after chronic morphine treatment and 19 transcripts were downregulated in the rat LC. After morphine withdrawal, 64 transcripts were upregulated and 40 were downregulated. Although the rat and mouse arrays contain different sets of genes, we found numerous genes that are commonly regulated in the two species. These genes are listed in Table 1, and they include several genes that have been identified previously as being morphine regulated in the LC. In fact, a number of the genes regulated in both mice and rats have been shown previously to be regulated by morphine or involved in morphine-related behavioral responses, which gives us a high degree of confidence in our methods (supplemental Table S6, available at www.jneurosci.org as supplemental material). There are also several regulated genes that are novel.

\section{Functional and cluster analysis of morphine- and withdrawal-} regulated genes in the $\mathrm{LC}$

The cAMP pathway and CREB have been implicated as important mediators of morphine- and withdrawal-induced changes in gene expression in the LC (Lane-Ladd et al., 1997; Nestler and Aghajanian, 1997). Therefore, we wanted to determine whether any of the genes that we see regulated in our study are CAMP- or CREB-responsive genes. We found that $\sim 20 \%$ of the genes regulated in mice or rats are known to be regulated by cAMP or CREB or contain known consensus CRE sites within their promoters (Table 2). These results further increase our confidence in this assay and confirm the importance of the CAMP-CREB path- 
way in mediating the effects of chronic morphine and morphine withdrawal in the LC. At the same time, the findings highlight the involvement of numerous additional mechanisms that are likely involved.

We next wanted to put the genes regulated in the LC into a functional context. We found that chronic morphine or morphine withdrawal upregulates several key genes involved in LC neurotransmission, including three genes encoding norepinephrine synthetic enzymes (tyrosine hydroxylase, dopamine $\beta$-hydroxylase, and aromatic acid decarboxylase), monoamine oxidase A, vesicular monoamine transporter, vesicle-associated membrane protein, and two genes encoding colocalized neuropeptides (galanin and prodynorphin) (supplemental Table S8A, available at www.jneurosci.org as supplemental material). These findings are consistent with the increase in noradrenergic transmission associated with the morphine-dependent state (Aghajanian, 1978). In addition, morphine withdrawal induced dramatic changes in clusters of genes involved in cell signaling, cell structure, and stress and immune responses. These include several protein kinases, structural molecules, metallothioneins, and heat shock proteins (supplemental Table S8B, available at www.jneurosci.org as supplemental material).

It also was of interest to compare global patterns of gene expression in the LC after chronic morphine versus withdrawal. For this, we used a hierarchical cluster analysis based on standard correlations. Regulated genes fell into several clusters. Some were upregulated or downregulated under both chronic morphine and withdrawal conditions. Some went from unchanged after chronic morphine to upregulated or downregulated during withdrawal, whereas still others reversed their expression under these two conditions (Figs. 1,2). Many of the genes that show an upregulation after both chronic morphine and withdrawal are involved in norepinephrine synthesis and transmission, as mentioned above, and include tyrosine hydroxylase, dopamine $\beta$-hydroxylase, aromatic acid decarboxylase, monoamine oxidase A, vesicular monoamine transporter, and plasma membrane norepinephrine transporter. Those genes that are upregulated by chronic morphine and then unchanged or downregulated after withdrawal include several genes involved in cell metabolism, such as aldolase A, phosphofructokinase-M, stearoyl-CoA desaturase 2, and cytochrome $\mathrm{P} 450$. As well, two $\mathrm{GABA}_{\mathrm{B}}$ receptor subunits and several RNA binding proteins fall in this category. Several genes that are involved in cell growth and differentiation are downregulated or unchanged by chronic morphine but are upregulated during withdrawal, including hepatocyte growth factor, nerve growth factor-induced factor A, and NeuroD1, along with structural genes including $\alpha$-actin, $\alpha_{1}$-collagen, and actin filament-binding protein. These findings highlight the complexity in gene expression changes that accompany morphine dependence and morphine withdrawal.

\section{Regulation of gene expression in the VTA}

We next examined regulation of gene expression in the VTA. Like the LC, the VTA is a brainstem catecholaminergic nucleus but, unlike the LC, is integrally involved in morphine reward rather than physical dependence. There were 16 significantly upregulated transcripts in the mouse VTA and 16 downregulated transcripts after chronic morphine treatment (supplemental Table S5, available at www.jneurosci.org as supplemental material). The upregulated genes include two ATPase transporting proteins, the dopamine transporter, and genes involved in regulating transcription, including nuclear factor $\kappa \mathrm{B}$ inhibitor, X-box binding protein 1, and two zinc finger proteins. The downregulated genes include several that are involved in lipid movement or metabolism, such as phospholipid transfer protein, stearoylcoenzyme A desaturase 1, farnesyl diphosphate synthase, and brain fatty acid-binding protein 7 .

There were 26 transcripts significantly upregulated in the VTA by morphine withdrawal and 46 downregulated (supplemental Table S6, available at www.jneurosci.org as supplemental material). Among the upregulated genes are several involved in stress responses, cell protection, and apoptosis, including two heat shock proteins, metallothionein $2, \mathrm{I} \kappa \mathrm{B} \alpha$, cyclin-dependent kinase inhibitor $1 \mathrm{~A}$, serum/glucocorticoid regulated kinase, HIF1-responsive RTP801, FK506 binding protein 5, and homer 1A. The downregulated genes again include several involved in maintenance of lipids, as well as several structural proteins, such as actin-related protein 2, kinesin heavy chain (A and C), matrin 3, and microtubule-associated protein 2 .

As with the LC, many of the genes found to be regulated in the 


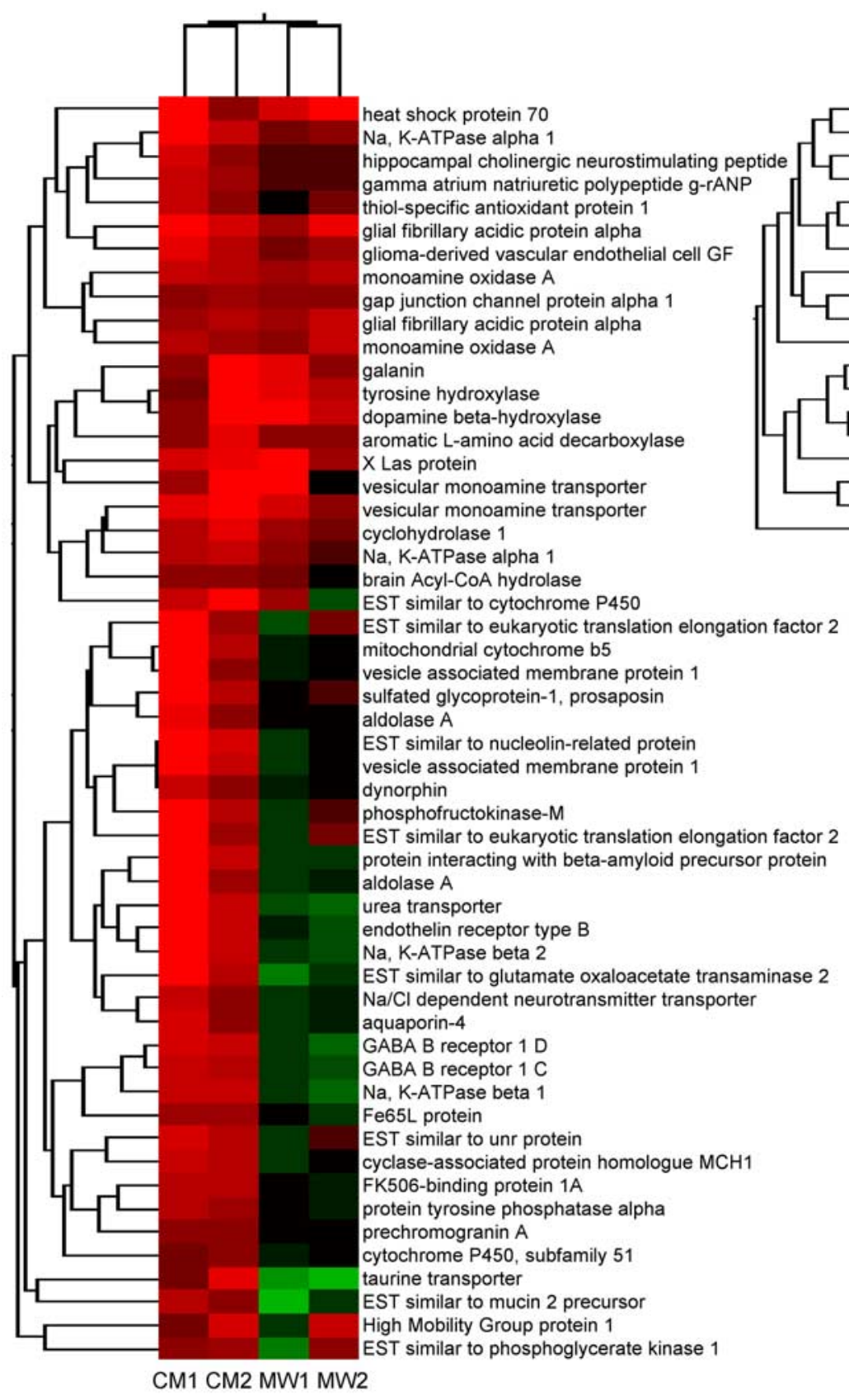

Figure 1. Hierarchical clusters of genes regulated by chronic morphine in the rat $\mathrm{LC}$ and how they are affected by morphine withdrawal. Hierarchical cluster analysis was based on changes from duplicate arrays using standard correlations and are colored using a heat map (red, upregulated; green, downregulated). The figure shows genes that are significantly upregulated (left) or downregulated (right) by chronic morphine in the $\mathrm{LC}$ and how they respond after morphine withdrawal. Genes listed more than once were identified multiple times on the array.

VTA have been implicated previously in morphine action in this or some other brain region (supplemental Table S6, available at www.jneurosci.org as supplemental material). In addition, we verified morphine or withdrawal regulation of a subset of genes altered in the VTA (supplemental Table S7, available at www. jneurosci.org as supplemental material) by real-time PCR and again found a false-positive rate of $<10 \%$.

When we compared the gene expression profiles between the VTA and LC, we found that most gene expression changes seen with chronic morphine are unique to each brain region. A dramatic example of such VTA-LC differences is tyrosine hydroxylase, which showed upregulation in the LC but no significant regulation in the VTA in our array experiments. This is interest- ing in light of previous studies that have shown that, although tyrosine hydroxylase protein levels are increased in both regions by chronic morphine, the tyrosine hydroxylase gene promoter is induced by chronic morphine in the LC only (Beitner-Johnson and Nestler, 1991; Boundy et al., 1998). Thus, even common adaptations seen in the two brain regions at the protein level may be generated via very different molecular mechanisms.

In striking contrast, after withdrawal, the patterns of gene expression that occur are very similar between the two brain regions (Figs. 3, 4). This suggests that chronic morphine produces mostly unique changes in different brain regions, whereas withdrawal may produce a more global response in gene regulation. 


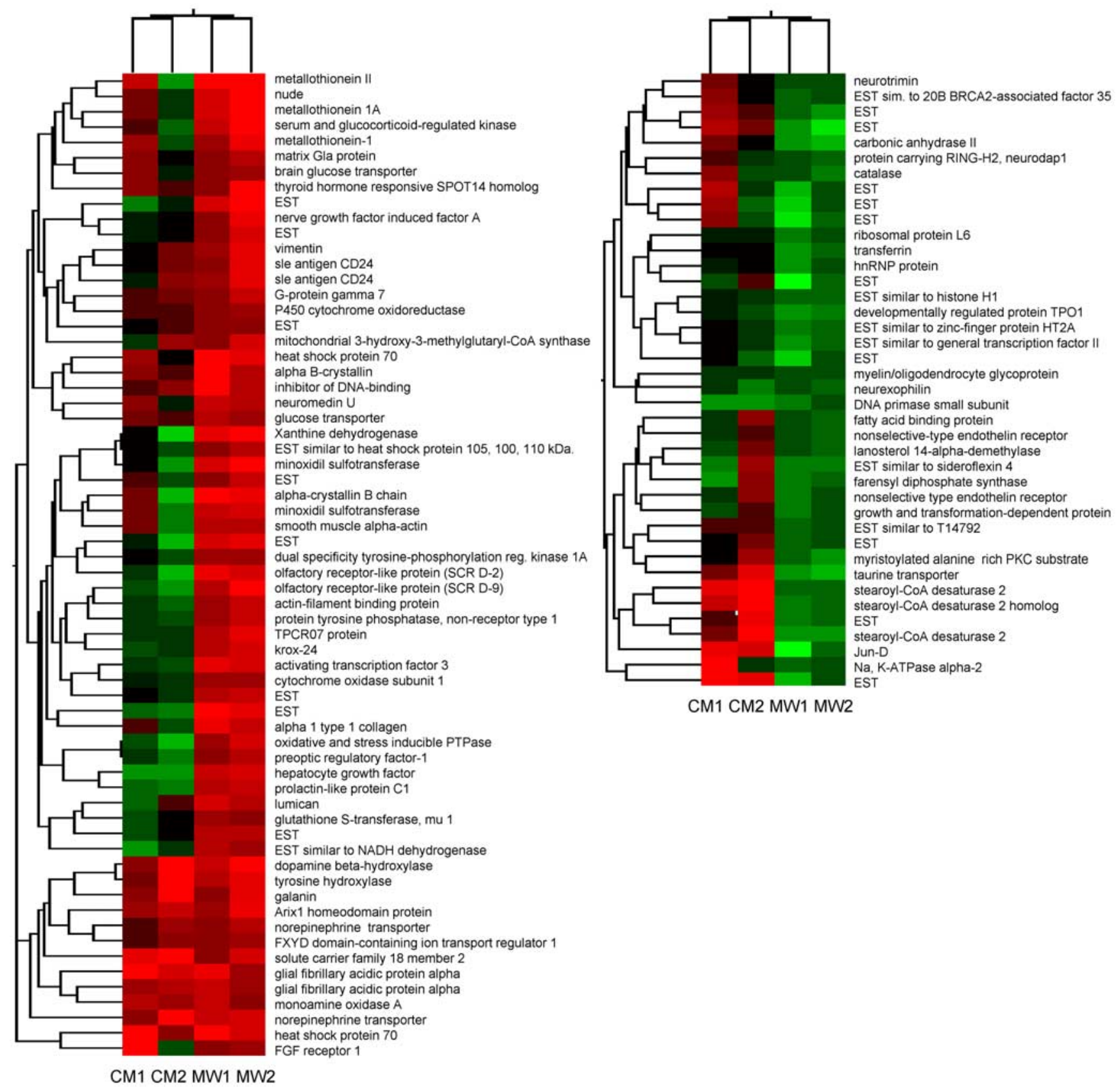

Figure 2. Hierarchical clusters of genes regulated by morphine withdrawal in the rat $\mathrm{L} C$ and how they are affected by chronic morphine. Hierarchical cluster analysis was based on changes from duplicate arrays using standard correlations and are colored using a heat map (red, upregulated; green, downregulated). The figure shows genes that are significantly upregulated (left) or downregulated (right) after morphine withdrawal in the $\mathrm{LC}$ and how they respond after chronic morphine.

\section{Functional studies of two morphine-regulated genes}

To demonstrate the utility of the gene expression array findings outlined above, we investigated the roles of two genes, prodynorphin and FKBP5, in morphine dependence. These genes show a high degree of regulation in the mouse LC after chronic morphine or morphine withdrawal (FKBP5). As well, prodynorphin and a protein similar to FKBP5, FKBP1a, were also regulated in the rat LC. Dynorphin is an opioid peptide that functions primarily as a $\kappa$-opioid receptor agonist, and dynorphin levels have been shown previously to be regulated in several brain regions and spinal cord after morphine treatment (Rattan et al., 1992; Georges et al., 1999). However, the role of dynorphin in withdrawal-associated behaviors is unclear (Simonin et al., 1998;
Cui et al., 2000). FKBP5 functions as a cochaperone of heat shock protein 90 and regulates glucocorticoid receptor sensitivity (Sinars et al., 2003). The regulation of FKBP5 (or other FK506 binding proteins) after morphine treatment, and the function of these proteins in morphine dependence and withdrawal, has not been examined to date. However, administration of FK506 itself has been shown to reduce tolerance to morphine-induced antinoception and reduce weight loss after naloxone-precipitated withdrawal (Homayoun et al., 2003), suggesting that FKBP5 may also play a role in these responses.

We first wanted to determine whether these two genes are enriched in the LC and whether we could replicate our microarray and real-time PCR data by quantitative in situ hybridization. 

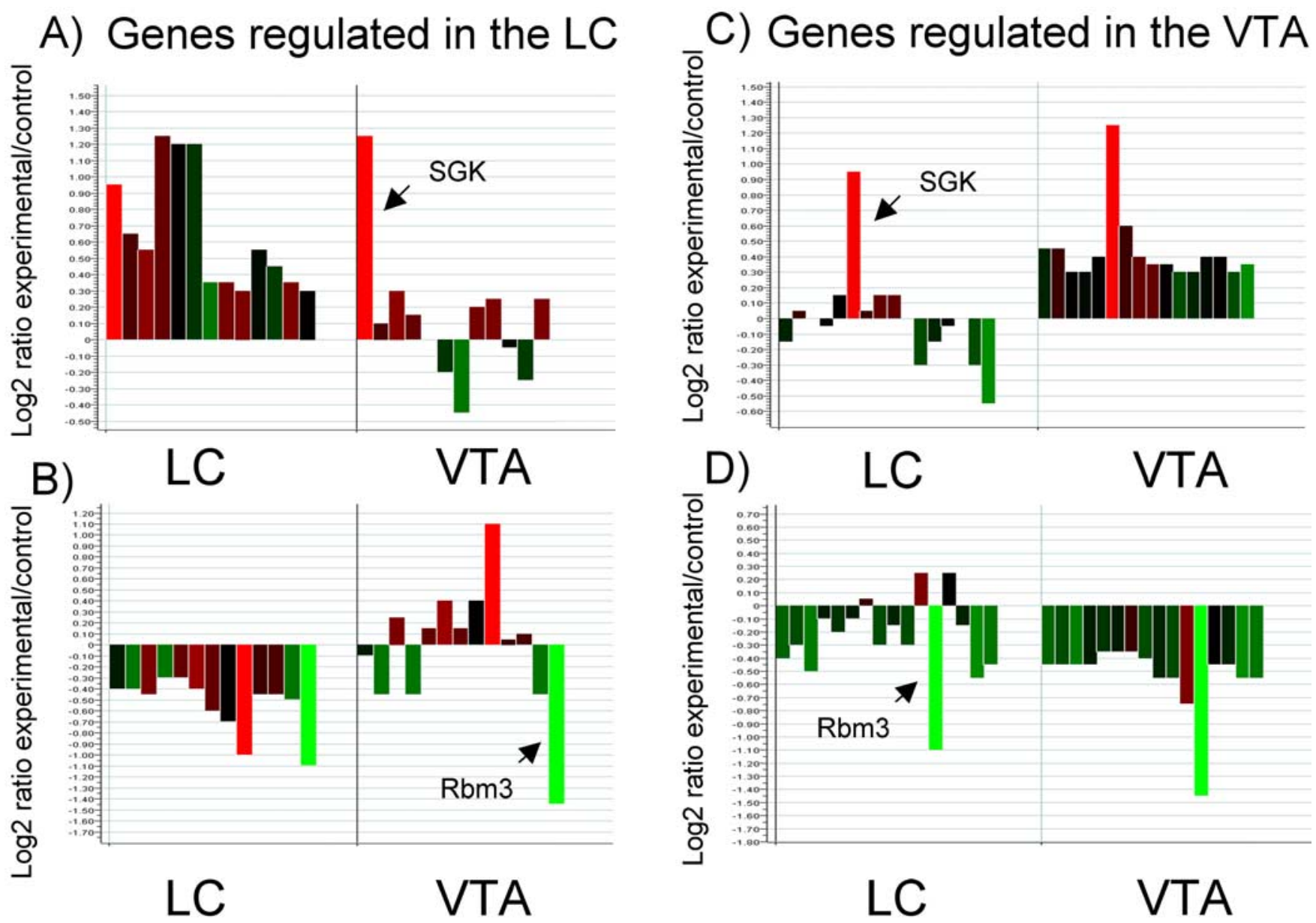

Figure 3. Comparison of gene expression changes found in the $\mathrm{LC}$ and VTA after chronic morphine. Mice were treated with chronic morphine over $6 \mathrm{~d}$, LC and VTA punches were taken and pooled on day 6 , and RNA was isolated, labeled, and subjected to microarray analysis. $A$, Genes that are significantly upregulated by chronic morphine in the $L C$ and how these genes are altered in the VTA. $B$, Genes that are significantly downregulated by chronic morphine in the LC and how they are altered in the VTA. C, Genes that are significantly upregulated in the VTA by chronic morphine and how they are altered in the LC. D, Genes that are significantly downregulated by chronic morphine in the VTA and how they are altered in the LC. Note: The serum glucocorticoid regulated kinase (SGK) gene and the RNA binding motif protein $3(\mathrm{Rbm} 3)$ gene show a significant regulation by chronic morphine in both the LC and VTA and are noted on the graph by an arrow.

Indeed, as expected, both genes show relatively high basal expression in the LC as well as increased mRNA levels in this region after chronic morphine treatment or naltrexone-precipitated withdrawal (Fig. 5).

We next determined whether blocking the functions of these proteins would affect morphine dependence. We used tacrolimus, a compound known to block the actions of FK506 binding proteins, and Nor-BNI, a $\kappa$-opioid receptor antagonist that blocks the actions of dynorphin. Administration of tacrolimus concomitantly with morphine resulted in a milder opiate withdrawal syndrome compared with vehicle-treated animals (Table 3). In contrast, administration of tacrolimus immediately before naltrexone in morphine-dependent animals did not affect the severity of opiate withdrawal (data not shown). These findings implicate FKBP5 in the development of morphine physical dependence but not in its expression. The converse was observed with Nor-BNI, which decreased the severity of the withdrawal syndrome when given just before naltrexone (Table 3) but did not influence the development of physical dependence when given concomitantly with morphine (data not shown). These findings implicate prodynorphin in the expression of morphine withdrawal but not in its development. Together, our results demonstrate that genes identified on DNA microarrays as being regulated by chronic morphine or morphine withdrawal can be anatomically verified by in situ hybridization and can then be used to explore new leads in the biological mechanisms governing morphine dependence and withdrawal syndromes.

\section{Discussion}

Results of the present study show that chronic morphine and precipitated morphine withdrawal lead to both specific as well as more global changes in gene expression in the LC and VTA. We have a high degree of confidence in these array findings for several reasons. First, we used Affymetrix chips in which each gene is represented multiple times. Second, we used rigorous statistical analysis to identify regulated genes with $\alpha=0.01$. Third, for each array, the RNA used was from samples pooled from three to five animals in each group, which decreases differences attributable to individual variability and increases the statistical power of these experiments (Peng et al., 2003). Each drug treatment group is compared directly with saline-treated controls, which were handled, treated, and killed at the same time, under the same conditions. As well, the RNA is isolated and labeled, and arrays are run at the same time for each experiment. Statistical analysis of the data indicated a false discovery rate of $\sim 0.1$ for all arrays in this study, and control experiments revealed that an extremely small number of transcripts $(\sim 0.035 \%)$ might be regulated by external variables, such as differences between animals, their environ- 

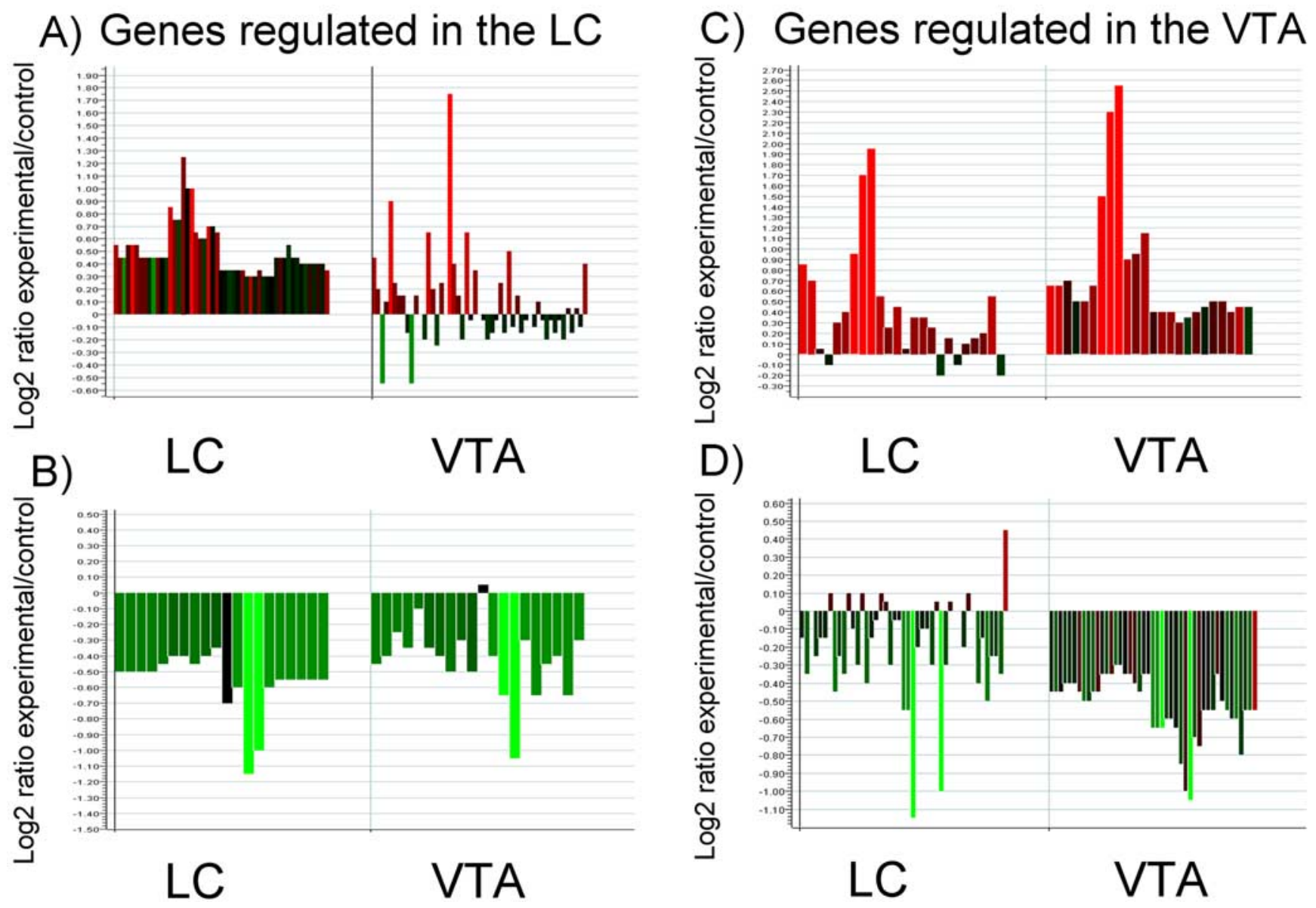

Figure 4. Comparison of gene expression changes found in the LC and VTA after precipitated morphine withdrawal. Mice were treated with chronic morphine over $6 \mathrm{~d}$, followed by a single administration of naltrexone on day 6. LC and VTA punches were taken $4 \mathrm{~h}$ later, and RNA was isolated, labeled, and subjected to microarray analysis. $A$, Genes that are significantly upregulated in the $L C$ after morphine withdrawal and how these genes are altered in the VTA. $B$, Genes that are significantly downregulated in the LC after morphine withdrawal and how they are altered in the VTA. C, Genes that are significantly upregulated in the VTA after morphine withdrawal and how they are altered in the LC. $\boldsymbol{D}$, Genes that are significantly downregulated in the VTA after morphine withdrawal and how they are altered in the LC.

ment, or technical deviations (see Materials and Methods). Fourth, all arrays were performed in duplicate or triplicate using separate groups of animals. Under these conditions, when noise (i.e., "absent" genes) are excluded, Affymetrix arrays have been shown to achieve a statistical power of $>0.99$ to detect twofold changes and 0.8-0.9 for 1.5-fold changes (Shippy et al., 2004). Fifth, many of the genes that we find regulated in the LC and VTA have been reported previously to be involved in responses to morphine in this or some other brain region (supplemental Table S6, available at www.jneurosci.org as supplemental material). In addition, when we attempted to verify morphine or withdrawal regulation of 26 representative genes by real-time PCR on separate pools of animals (supplemental Table S8, available at www. jneurosci.org as supplemental material), all but one of the changes were replicable, consistent with our experience of $<10 \%$ false positives with our methodology (McClung and Nestler, 2003). These findings further confirm the validity of the gene sets described here.

Among the genes regulated in the LC by chronic morphine and morphine withdrawal are those involved in noradrenergic neurotransmission, including tyrosine hydroxylase, dopamine $\beta$-hydroxylase, and aromatic amino acid decarboxylase. An upregulation of these genes would be expected to increase the synthesis of norepinephrine. It has been shown that norepinephrine levels are increased in the LC and its target regions after precipi- tated withdrawal and are believed to contribute to particular withdrawal symptoms (Taylor et al., 1988; Nakai et al., 2002). Upregulation of these genes could support the increased noradrenergic transmission seen during withdrawal. In other cases, changes in gene expression appear to represent compensatory mechanisms that oppose the actions of morphine. For example, galanin is significantly upregulated in mouse and rat LC. Galanin is also a CREB target (Corness et al., 1997), and recent studies have suggested that overexpression of galanin in noradrenergic neurons results in a milder withdrawal syndrome (Zachariou et al., 2003a). Another example is the $\mathrm{GABA}_{\mathrm{B}}$ receptor (1C and $1 \mathrm{D}$ subunits), which we find to be upregulated in our studies. The GABAergic system inhibits neuronal activity in the LC (AhmadiAbhari et al., 2001), and the observed upregulation in these receptor subunits could also be perceived as a compensatory adaptation. Chronic morphine and withdrawal produce changes in several other genes that are known to be downstream of cAMP and CREB, which supports the hypothesis that the CAMP-CREB pathway is highly involved in the long-term changes produced by chronic morphine in the LC. Regulation of many of these cAMPCREB-dependent genes is more dramatic during withdrawal than after chronic morphine per se, as would be expected, because removal of opiate during withdrawal unmasks the full functional potential of the upregulated cAMP pathway in these neurons (Nestler and Aghajanian, 1997). 


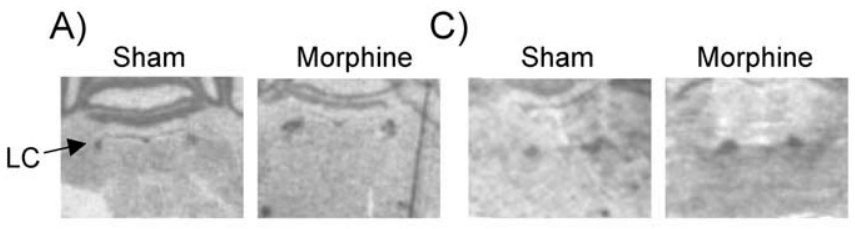

B)
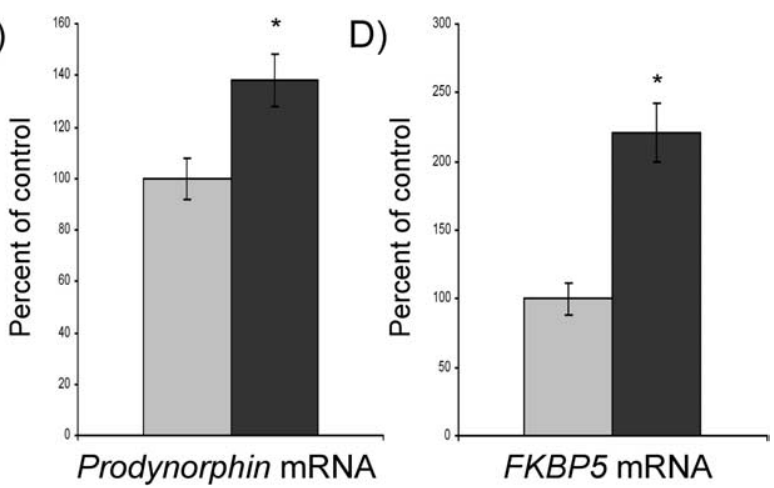

Figure 5. Expression of prodynorphin and FKBP5 in the $L C$ and induction after morphine treatment and/or withdrawal. $\boldsymbol{A}$, Representative sections showing prodynorphin expression in the LC in sham-treated animals and animals treated chronically with morphine. B, Quantification of prodynorphin mRNA expression from in situ hybridizations. The light bar represents sham treatment, and the dark bar represents morphine treatment. ${ }^{*} p<0.05$ by ANOVA; $n=$ 5-6. C, Representative sections showing FKBP5 expression in the LC in sham, naltrexonetreated animals and animals treated chronically with morphine followed by naltrexoneprecipitated withdrawal. D, Quantification of FKBP5 mRNA expression from in situ hybridizations. The light bar represents sham treatment, and the dark bar represents morphine withdrawal. ${ }^{*} p<0.05$ by ANOVA; $n=7-10$.

Morphine withdrawal produced a larger number of gene expression changes compared with chronic morphine. Many of these withdrawal-regulated genes are involved in cell signaling, as well as stress and immune responses, such as several heat shock proteins, $\alpha$ crystallin B, and the metallothioneins. Previous studies have implicated many of these same genes in morphine action. For example, the metallothionein genes are regulated by morphine in the brain and liver (Hidalgo et al., 1991; Florianczyk and Stryjecka-Zimmer, 2001). We also find numerous genes that have not been identified previously as important in morphine action, including $\alpha$ B-crystallin, farnesyl diphosphate synthetase, aquaporin 4, FK506 binding proteins (5 and 1a), prosaposin, and hippocampal cholinergic neurostimulating peptide.

Many of the gene expression changes observed in the LC are consistent between mice and rats (Table 1). This is even more striking given that the mouse and rat arrays used contain different sets of genes. These results give credence to our assay, because mice and rats have similar behavioral and biochemical responses to morphine and withdrawal. It also pinpoints genes that may be more important for morphine action, such as tyrosine hydroxylase, galanin, prodynorphin, ATPase $\alpha 1$, and glutamic acid decarboxylase, which show similar regulation in the LC of both species. However, because not all genes that were regulated on the mouse array are included on the rat array and vice versa, the lack of common regulation between mice and rats must be viewed with caution. Moreover, a small number of genes showed opposite regulation in the mouse and rat LC, and these too might be interesting candidates for future studies, although, as with all array studies, these opposing effects could be attributable to false discoveries or technical variability from the two arrays. A larger number of genes were found to change in rat versus mouse LC. This could be attributable to the particular genes on the two arrays or to the lower variability and hence greater homogeneity in LC dissections from the larger rat brain.

We wanted to determine how gene expression changes that occur in a major noradrenergic nucleus of brain (LC) compare with those seen in a dopaminergic nucleus (VTA). Interestingly, we found that the changes that occur after chronic morphine are relatively specific to the LC or VTA. In contrast, changes seen during morphine withdrawal are very similar between the two brain regions. Consistent with this conclusion are the results from a recent study that examined changes in gene expression after chronic morphine and morphine withdrawal in frontal cortex (Ammon et al., 2003). This study reported many of the same genes regulated in cortex during withdrawal as we find in the LC and VTA. These genes, which include $\mathrm{I} \kappa \mathrm{B}$, serum glucocorticoidregulated kinase, preoptic regulatory factor 1 , metallothionein 1 and 2, and minoxidil sulfotransferase, support the view that precipitated withdrawal produces more global changes in gene expression than chronic morphine per se. It is also apparent that prominent among these global changes are genes involved in stress and immune responses, which demonstrates the degree to which opiate withdrawal places an extraordinary functional and metabolic stress on the brain. Additional studies are needed to determine whether acute treatments or longer withdrawal time points may identify other interesting similarities or differences in gene expression changes between the LC and VTA.

Interestingly, both chronic morphine and morphine withdrawal lead to a downregulation in several genes involved in lipid movement and processing in the VTA. Previous studies have shown that brain phospholipid content is reduced in rats with morphine physical dependence (Selevich and Lelevich, 1997; Hula et al., 1998). In addition, methadone treatment in opiatedependent patients leads to elevated percentages of phosphomonoesters and phosphodiesters (Silveri et al., 2004). This altered phospholipid metabolism is suggestive of alterations in membrane turnover, proliferation, or remodeling. Furthermore, administration of citicoline, which increases the production of membrane phospholipids, can attenuate some measures of craving in cocaine-dependent patients (Renshaw et al., 1999). It will be interesting to determine whether the reduction that we see in lipid processing genes in the VTA is involved in altering dopaminergic transmission during morphine exposure or withdrawal.

We chose two genes that were highly regulated after chronic morphine or morphine withdrawal (prodynorphin and FKBP5) and examined the behavioral consequences of blocking the function of these genes. Blockade of prodynorphin by Nor-BNI caused a milder withdrawal syndrome, whereas blockade of

Table 3. Effect of tacrolimus ( $5 \mathrm{mg} / \mathrm{kg}$, i.p.) and Nor-BNI ( $5 \mathrm{mg} / \mathrm{kg}$, i.p.) on opiate withdrawal behavior in mice

\begin{tabular}{|c|c|c|c|c|c|c|}
\hline & Jumps & Wet dog shakes & Ptosis & Tremor & Diarrhea & Weight loss \\
\hline Tacrolimus & $61.3 \pm 16.8^{*}$ & $58.5 \pm 14.8^{*}$ & $57 \pm 19^{*}$ & $88 \pm 5.6$ & $42.9 \pm 17.7^{*}$ & $50.3 \pm 13.6^{*}$ \\
\hline Nor-BNI & $71 \pm 7^{*}$ & $95 \pm 25$ & $63 \pm 5^{*}$ & $96 \pm 11$ & $46 \pm 12^{*}$ & $68 \pm 13^{*}$ \\
\hline
\end{tabular}

Data are expressed as mean \pm SEM percentage of control (mice that received chronic morphine, naltrexone, and vehicle injections instead of tacrolimus or Nor-BNI). ${ }^{*} p<0.05, t$ test. $n=5$ per group. The raw values for withdrawal signs for the vehicle-treated mice in the tacrolimus group are as follows: jumps, $82 \pm 11.9$; wet dog shakes, $10.6 \pm 2$; diarrhea, $8.4 \pm 1.5$; tremor, $5.0 \pm 0$; ptosis, $4.6 \pm 0.2 ;$ weight loss (in grams), 3.3 \pm 0.3 . For Nor-BNI, the raw values are as follows: jumps, $130 \pm 18$; wet dog shakes, $12.6 \pm 2.4$; diarrhea, $9.2 \pm 0.8$; ptosis, $4.4 \pm 2$; tremor, $4.4 \pm 0.2$; weight loss, $3.0 \pm 0.3$. 
FKBP5 with tacrolimus attenuated the development of physical dependence. Overexpression of FKBP5 in New World primates alters glucocorticoid levels and physiological effects (Scammell et al., 2001), and polymorphisms in the FKBP5 gene in humans have been associated with depression (Binder et al., 2004). This regulation of the hypothalamic-pituitary-adrenal axis by FKBP5 may also contribute to the development of opiate dependence. Our functional data suggest that, whereas prodynorphin appears more involved in the expression of withdrawal, FKBP5 is more involved in the development of dependence. These data support the ability of microarray studies such as this to identify genes important for functional responses to morphine.

In conclusion, these studies identify sets of genes that are likely important in morphine action at the cellular level in the LC and VTA and thereby contribute to the different aspects of morphine dependence, reward, and addiction mediated by these two brain regions. Future studies can now evaluate these regulated genes, individually and in groups, to determine the important roles they play in morphine-induced molecular and behavioral plasticity.

\section{References}

Aghajanian GK (1978) Tolerance of locus coeruleus neurons to morphine and suppression of withdrawal response by clonidine. Nature 276:186-188.

Aghajanian GK, Wang YY (1986) Pertussis toxin blocks the outward currents evoked by opiate and alpha 2-agonists in locus coeruleus neurons. Brain Res 371:390-394.

Ahmadi-Abhari SA, Akhondzadeh S, Assadi SM, Shabestari OL, Farzanehgan ZM, Kamlipour A (2001) Baclofen versus clonidine in the treatment of opiates withdrawal, side-effects aspect: a double-blind randomized controlled trial. J Clin Pharm Ther 26:67-71.

Alvarez VA, Arttamangkul S, Dang V, Salem A, Whistler JL, Von Zastrow M, Grandy DK, Williams JT (2002) $\mu$-Opioid receptors: ligand-dependent activation of potassium conductance, desensitization, and internalization. J Neurosci 22:5769-5776.

Ammon S, Mayer P, Riechert U, Tischmeyer H, Hollt V (2003) Microarray analysis of genes expressed in the frontal cortex of rats chronically treated with morphine and after naloxone precipitated withdrawal. Brain Res Mol Brain Res 112:113-125.

Beitner-Johnson D, Nestler EJ (1991) Morphine and cocaine exert common chronic actions on tyrosine hydroxylase in dopaminergic brain reward regions. J Neurochem 57:344-347.

Benjamini Y, Hochberg Y (1995) Controlling the false discovery rate: a practical and powerful approach to multiple testing. J R Stat Soc Ser B 57:289-300.

Binder EB, Salyakina D, Lichtner P, Wochnik GM, Ising M, Putz B, Papiol S, Seaman S, Lucae S, Kohli MA, Nickel T, Kunzel HE, Fuchs B, Majer M, Pfennig A, Kern N, Brunner J, Modell S, Baghai T, Deiml T, et al (2004) Polymorphisms in FKBP5 are associated with increased recurrence of depressive episodes and rapid response to antidepressant treatment. Nat Gen 36:1319-1325.

Bonci A, Williams JT (1996) A common mechanism mediates long-term changes in synaptic transmission after chronic cocaine and morphine. Neuron 16:631-639.

Bonci A, Williams JT (1997) Increased probability of GABA release during withdrawal from morphine. J Neurosci 17:796-803.

Boundy VA, Gold SJ, Messer CJ, Chen J, Son JH, Joh TH, Nestler EJ (1998) Regulation of tyrosine hydroxylase promoter activity by chronic morphine in TH9.0-LacZ transgenic mice. J Neurosci 18:9989-9995.

Corness JD, Burbach JP, Hokfelt T (1997) The rat galanin-gene promoter: response to members of the nuclear hormone receptor family, phorbol ester and forskolin. Brain Res Mol Brain Res 47:11-23.

Cui CL, Wu LZ, Han JS (2000) Spinal kappa-opioid system plays an important role in suppressing morphine withdrawal syndrome in the rat. Neurosci Lett 295:45-48.

Fitzgerald LW, Ortiz J, Hamedani AG, Nestler EJ (1996) Drugs of abuse and stress increase the expression of GluR1 and NMDAR1 glutamate receptor subunits in the rat ventral tegmental area: common adaptations among cross-sensitizing agents. J Neurosci 16:274-282.
Florianczyk B, Stryjecka-Zimmer M (2001) Induction of metallothioneins by ethanol and morphine. Ann Univ Mariae Curie Sklodowska [Med] 56:183-187.

Georges F, Stinus L, Bloch B, Le Moine C (1999) Chronic morphine exposure and spontaneous withdrawal are associated with modifications of dopamine receptor and neuropeptide gene expression in the rat striatum. Eur J Neursci 11:481-490.

Gold SJ, Han MH, Herman AE, Ni YG, Pudiak CM, Aghajanian GK, Liu RJ, Potts BW, Mumby SM, Nestler EJ (2003) Regulation of RGS proteins by chronic morphine in rat locus coeruleus. Eur J Neurosci 17:971-980.

Guitart X, Thompson MA, Mirante CK, Greenberg ME, Nestler EJ (1992) Regulation of cyclic AMP response element-binding protein (CREB) phosphorylation by acute and chronic morphine in the rat locus coeruleus. J Neurochem 58:1168-1171.

Harris GC, Williams JT (1991) Transient homologous mu-opioid receptor desensitization in rat locus coeruleus neurons. J Neurosci 11:2574-2581.

Hidalgo J, Giralt M, Garvey JS, Armario A (1991) Effect of morphine administration on rat liver metallothionein and zinc metabolism. J Pharmacol Exp Ther 259:274-278.

Homayoun H, Khavandgar S, Mehr S, Ejtemaei S, Namiranian K, Dehpour AR (2003) The effects of FK506 on the development and expression of morphine tolerance and dependence in mice. Behav Pharm 14: 121-127.

Hula NM, Marhitych VM, Hovseieva NM, Klimashevs'kyi VM, Zhukov OD, Synyts'kyi VM (1998) Brain lipid composition of the rat with experimental morphine dependence. Ukr Biokhim Zh 70:98-105.

Inturrisi CE (2002) Clinical pharmacology of opioids for pain. Clin J Pain 18:S3-S13.

Ivanov A, Aston-Jones G (2001) Local opiate withdrawal in locus coeruleus neurons in vitro. J Neurophysiol 85:2388-2397.

Kaminska B, Gaweda-Walerych K, Zawadzka M (2004) Molecular mechanisms of neuroprotective action of immunosuppressants-facts and hypotheses. J Cell Mol Med 8:45-58.

Kieffer BL, Gaveriaux-Ruff C (2002) Exploring the opioid system by gene knockout. Prog Neurobiol 66:285-306.

Kreek MJ (2001) Drug addictions. Molecular and cellular endpoints. Ann NY Acad Sci 937:27-49.

Lane-Ladd SB, Pineda J, Boundy VA, Pfeuffer T, Krupinski J, Aghajanian GK, Nestler EJ (1997) CREB (cAMP response element-binding protein) in the locus ceruleus: biochemical, physiological, and behavioral evidence for a role in opiate dependence. J Neurosci 17:7890-7901.

McClung CA, Nestler EJ (2003) Regulation of gene expression and cocaine reward by CREB and $\triangle F$ FosB. Nat Neurosci 6:1208-1215.

Nakai T, Hayashi M, Ichihara K, Wakabayashi H, Hoshi K (2002) Noradrenaline release in rat locus coeruleus is regulated by both opioid and alpha(2)-adrenoceptors. Pharmacol Res 45:407-412.

Narita M, Funada M, Suzuki T (2001) Regulations of opioid dependence by opioid receptor types. Pharmacol Ther 89:1-15.

Nestler EJ, Aghajanian GK (1997) Molecular and cellular basis of addiction. Science 278:58-63.

Nye HE, Nestler EJ (1996) Induction of chronic Fos-related antigens in rat brain by chronic morphine administration. Mol Pharmacol 49:636-645.

Peng X, Wood CL, Blalock EM, Chen KC, Landfield PW, Stromberg AJ (2003) Statistical implications of pooling RNA samples for microarray experiments. BMC Bioinformatics 4:26-34.

Punch L, Self DW, Nestler EJ, Taylor JR (1997) Opposite modulation of opiate withdrawal behaviors upon microinfusion of a protein kinase A inhibitor versus activator into the locus coeruleus or periaqueductal gray. J Neurosci 17:8520-8527.

Rasmussen K, Beitner-Johnson DB, Krystal JH, Aghajanian GK, Nestler EJ (1990) Opiate withdrawal and the rat locus coeruleus: behavioral, electrophysiological, and biochemical correlates. J Neurosci 10:2308-2317.

Rattan AK, Koo KL, Tejwani GA, Bhargava HN (1992) The effect of morphine tolerance dependence and abstinence on immunoreactive dynorphin (1-13) levels in discrete brain regions, spinal cord, pituitary gland and peripheral tissues of the rat. Brain Res 584:207-212.

Renshaw PF, Daniels S, Lundahl LH, Rogers V, Lukas SE (1999) Short-term treatment with citicoline (CDP-choline) attenuates some measures of craving in cocaine-dependent subjects: a preliminary report. Psychopharmacology 142:132-138.

Scammell JG, Denny WB, Valentine DL, Smith DF (2001) Overexpression of the FK506-binding immunophilin FKBP51 is the common cause of 
glucocorticoid resistance in three new world primates. Gen Comp Endocrin 124:152-165.

Selevich MI, Lelevich VV (1997) Effect of chronic morphine administration on concentrations of individual lipids in various rat brain structures. Ukr Biokhim Zh 69:107-110.

Self DW, McClenahan AW, Beitner-Johnson D, Terwilliger RZ, Nestler EJ (1995) Biochemical adaptations in the mesolimbic dopamine system in response to heroin self-administration. Synapse 21:312-318.

Shaw-Lutchman TZ, Barrot M, Wallace T, Gilden L, Zachariou V, Impey S, Duman RS, Storm D, Nestler EJ (2002) Regional and cellular mapping of cAMP response element-mediated transcription during naltrexoneprecipitated morphine withdrawal. J Neurosci 22:3663-3672.

Shippenberg TS, Rea W (1997) Sensitization to the behavioral effects of cocaine: modulation by dynorphin and kappa-opioid receptor agonists. Pharmacol Biochem Behav 57:449-455.

Shippy R, Sendera TJ, Lockner R, Palaniappan C, Kaysser-Kranich T, Watts G, Alsobrook J (2004) Performance evaluation of commercial shortoligonucleotide microarrays and the impact of noise in making crossplatform correlations. BMC Genomics 5:61-76.

Silveri MM, Pollack MH, Diaz CI, Nassar LE, Mendelson JH, Yurgelun-Todd DA, Renshaw PF, Kaufman MJ (2004) Cerebral phosphorus metabolite and transverse relaxation time abnormalities in heroin-dependent subjects at onset of methadone maintenance treatment. Psychiatry Res 131:217-226.

Simonin F, Valverde O, Smadja C, Slowe S, Kitchen I, Dierich A, Le Meur M,
Roques BP, Maldonado R, Kieffer BL (1998) Disruption of the kappaopioid receptor gene in mice enhances sensitivity to chemical visceral pain, impairs pharmacological actions of the selective kappa-agonist U-50,488H and attenuates morphine withdrawal, EMBO J 17:886-897.

Sinars C, Cheung-Flynn J, Rimerman RA, Scammell JG, Smith DF, Clardy J (2003) Structure of the large FK506-binding protein FKBP51, an Hsp90binding protein and a component of steroid receptor complexes. Proc Natl Acad Sci USA 100:868-873.

Taylor JR, Elsworth JD, Garcia EJ, Grant SJ, Roth RH, Redmond Jr DE (1988) Clonidine infusions into the locus coeruleus attenuate behavioral and neurochemical changes associated with naloxone-precipitated withdrawal. Psychopharmacology (Berl) 96:121-134.

Walters CL, Kuo YC, Blendy JA (2003) Differential distribution of CREB in the mesolimbic dopamine reward pathway. J Neurochem 87:1237-1244.

Widnell KL, Russell DS, Nestler EJ (1994) Regulation of expression of cAMP element-binding protein in the locus coeruleus in vivo and in a locus coeruleus-like cell line in vitro. Proc Natl Acad Sci USA 91:10947-10951.

Zachariou V, Brunzell DH, Hawes J, Stedman DR, Bartfai T, Steiner RA, Wynick D, Langel U, Picciotto MR (2003a) The neuropeptide galanin modulates behavioral and neurochemical signs of opiate withdrawal. Proc Natl Acad Sci USA 100:9028-9033.

Zachariou V, Georgescu D, Sanchez N, Rahman Z, DiLeone R, Berton O, Neve RL, Sim-Selley LJ, Selley DE, Gold SJ, Nestler EJ (2003b) Essential role for RGS9 in opiate action. Proc Natl Acad Sci USA 100:13656-13661. 